\section{ACUTE INTESTINAL OBSTRUCTION *}

BY

\author{
HERBERT J. PATERSON, C.B.E., M.D., M.Ch. \\ F.R.C.S. \\ SENIOR SLRGEON, NATIONAL TEMPERANCE HOSPITAL
}

General practitioners are often blamed for failure to recognize intestinal obstruction in its early stage. They are blamed most unjustly. In the early stage there is nothing more difficult to diagnose ; in the later stages the diagnosis is so easy that he who runs may read. I propose very briefly to mention a few only of the points which are of importance.

Early diagnosis is the key to success. Severe pain of sudden onset unaccompanied by rigidity or marked tenderness should always raise a suspicion of intestinal obstruction. When the pain is accompanied by rigidity the symptoms may suggest the perforation of a hollow viscus'. We are told in our textbooks that the rigidity of intestinal colic is superficial and less marked than in cases of perforation. This is not strictly true. The rigidity of intestinal colic may be board-like in its intensity, but there is an important difference. In intestinal colic, gentle massage with a warm hand will gradually overcome the rigidity ; in perforation, no coaxing will induce the muscles to relax their protective spasm. If, in addition to pain, there is inability to pass flatus or faeces, surgical treatment is indicated. A person who is passing neither wind nor faeces is a dying person. If this cannot be ascertained from the history of the illness the administration of two enemas at intervals of one hour, as indicated by Sir Henry Newland, will settle this point and confirm or negative the diagnosis.

The suggestion that radiography should be employed in the diagnosis of intestinal obstruction is one which should be condemned whole-heartedly. Sir Henry Newland has stressed the value of the "seeing eye," and I am in most cordial agreement with him. At the present time, there is a tendency to rely too much on laboratorymade diagnoses. I prefer the "seeing eye" of a living clinician to the scientific eye of a dead machine. Even if the diagnostic value of radiography in intestinal obstruction were more than problematical, the unfortunate patient,' by the time his examination and preparation are completed, has had quite sufficient test of his patience and endurance. In dealing with intestinal obstruction, the surgeon should have the courage of his convictions and get on with his job. I began my professional life as an anaesthetist, and my experience during the years I was resident at St. Bartholomew's Hospital taught me three important lessons. First, the importance to the patient of a short period of rest after the preparation for operation is completed-when the patient has been prepared, a small dose of morphine should be administered and the patient allowed to rest for at least half an hour. Secondly, the importance of keeping the patient warm. In more senses than one, a cold slab is the death-bed of the acute abdomen-a heated operation table is a vital necessity, and the patient's extremities should be bandaged in cotton-wool. Thirdly, that patients who are acutely ill will not stand prolonged operations. After half an hour the pulse begins to fail, and after forty-five minutes this failure becomes very pronounced.

The aim of treatment should thus be the relief of obstruction by the simplest method and in the shortest time possible. Two great principles should be observed: (1) no form of anastomosis or resection is permissible in cases of acute intestinal obstruction; and (2) drainage of the bowel should be established wherever necessary. I

* Paper read in the discussion in the Section of Surgery at th Centenary Meeting of the British Medical Association, London, 1932. am aware that at the present time drainage is not fashionab!e ; indeed, by some it is regarded as a confession of ignorance on the part of a stagnant and indecisive mind. This heresy is a heritage of the war, when claims were made as to the success of excision and primary suture of wounds which were not confirmed by those who witnessed the ultimate results of this method of treatment. If the obstruction cannot be removed, or if, after its removal, the intestine is too paralysed to empty itself, drainage of the bowel is imperative. In the statistics so admirably presented by Mr. Vick, resection was performed in 10 per cent. of the cases, and I think less heroic measures would result in a diminished mortality rate.

To sum up, the important points are: (a) early diagnosis and early operation; (b) preparation of the patient followed by a short period of rest ; $(c)$ a heated operation tab!e ; $(d)$ no resection or anastomosis ; $(e)$ drainage of the bowel when necessary-sepsis demands drainage; surely this is one of the eternal verities of surgery.

\section{STATISTICS OF ACUTE INTESTINAL OBSTRUCTION*}

BY

REGINALD M. VICK, M.CH., F.R.C.S.

SURGEON WITH CHARGE OF OCT-P.ITIENTS, ST. BARTHOLOMEW'S HOSPITAI.

In 1925, at a meeting of this Section of the $\Lambda$ ssociation at Bath, a very useful and interesting discussion took place on the subject of acute intestinal obstruction, and it was suggested that after the lapse of a few years the discussion should be repeated in order that all our ideas might be ventilated again and our knowledge brought up to date. Unlike most really useful suggestions this one has been carried out, and the stage is now set for another full-dress discussion on the diagnosis, treatment, and prognosis of the many conditions, all of them potentially serious, which are included under the wide term ". acute intestinal obstruction."

In $1925 \mathrm{Mr}$. Souttar presented a carefully prepared set of figures showing the results of treatment of cases of acute obstruction at seven large London hospitals during the years 1920 to 1925 . At the invitation of the officers of this Section I have prepared another series for the years 1925 to 1930 , and I have to thank Mr. Souttar for the use of all his available material and for his help. It has been my deliberate endeavour to adhere to the classification and arrangement adopted in 1925, in order that we may be enabled the better to compare the two sets of figures. This has worked out so satisfactorily that it would be possible, if it is considered advisable, for the two sets of figures to be fused together and thus give us records with a considerable amount of clinical detail of nearly 10,000 cases. I have introduced certain modifications and elaborations: my period is six years instead of five, and I have widened the scope of the investigation by collecting from twelve hospitals in London, eight in the provinces, and one in Scotland, making twenty-one in all. Although this return does not include any of the hundreds of cases operated upon in cottage hospitals or in private practice, it must be admitted to be a very representative statistical return.

I have listened far too often to the dreary recapitulation of statistics ever to wish to condemn even my greatest enemy to so unkind a fate, and I will communicate the figures to you as quickly and as painlessly as I can. First of all, I would call your attention to the graph which I have prepared. There, in diagrammatic form, I have set forth the facts. The number of cases is 6,892 . They

* Communicated to the Section of Surgery at the Centenary Meeting of the British Medical Association, London, 1932. 
are included under the nine main headings, some of the minor headings being omitted for the sake of clearness. The first set of columns shows the age incidence of the various types, indicating the proportion of cases occurring in each decade. These columns show that gall-stone obstruction occurs most-commonly between the ages of 50 and 70 ; obstruction as the result of carcinoma, in the sixth and seventh decades. Adhesions and internal strangulation are among the dangers of early adult life, while practically all the cases of idiopathic intussuscep- tion-940 out. of a total of 989-occur before the age of 10 , and most of them within the first two years of life. Volvulus occurs after the age of 40 , as a rule, and the age incidence of the various types of strangulated hernia is clearly shown. On the right of the graph you see represented the deaths and recoveries. By the shaded areas are represented all those who have to thank a wise doctor and a skilful surgeon for their lives, and by the black areas those who have died, often in the greatest misery and distress. The actual figures are represented on

\section{COMBINED STATISTICS OF TWENTY-ONE HOSPITALS FOR THE YEARS 1925-30 INCLUSIVE}

The statistics are compiled from the records of the following hospitals. After each hospital is given the name of the surgeon or registrar to whom thanks are due for collecting the data on which the return is based. The figures in parentheses indicate the number of cases at each place.

St. Bartholomew's Hospital (305) Mr. Naunton Morgan. Charing Cross Hospital

St. George's Hospital Guy's Hospital

King's College Hospital

London Hospital

St. Mary's Hospita

Niddlesex Hospital

St. Thomas's Hospital

University College Hospital

Westminster Hospital

Royal Free Hospital
(68) Mr. Fitzsimons.

(161) Mr. Marnham.

(207) Mr. Northfield.

(130) Mr. H. J. C. Wood

(130) Mr. H. J. C. Wood.

(104) Mr. Porritt.

(144) Mr. Wiles.

(384) Mr. Sworn.

(95) Mr. Flemming.

(66) Mr. Kendall.

(57) Miss G. Smith.
Royal Victoria Infirmary,

Newcastle-on-Tyne

Royal Infirmary, Manchester

General Hospital, Birmingham

Royal Infirmary, Liverpool

General Infirmary, Leeds

Royal Infirmary, Sheffield Royal Infirmary, Bristol

General Hospital, Bristol

Royal Infirmary, Edinburgh
$(1,019)$ Mr. G. A. Mason.

(1,011) Mr. Rowbotham.

(175) Mr. Fauset Welsh.

(88) Mr. Cosbie Ross.

(664) Mr. Armitage.

Mr. Pyrah.

(295) Mr. Holdsworth.

(322) Mr. Jackman.

(176) Mr. J. S. H. Griffiths.

(558) Mr. Weevil.

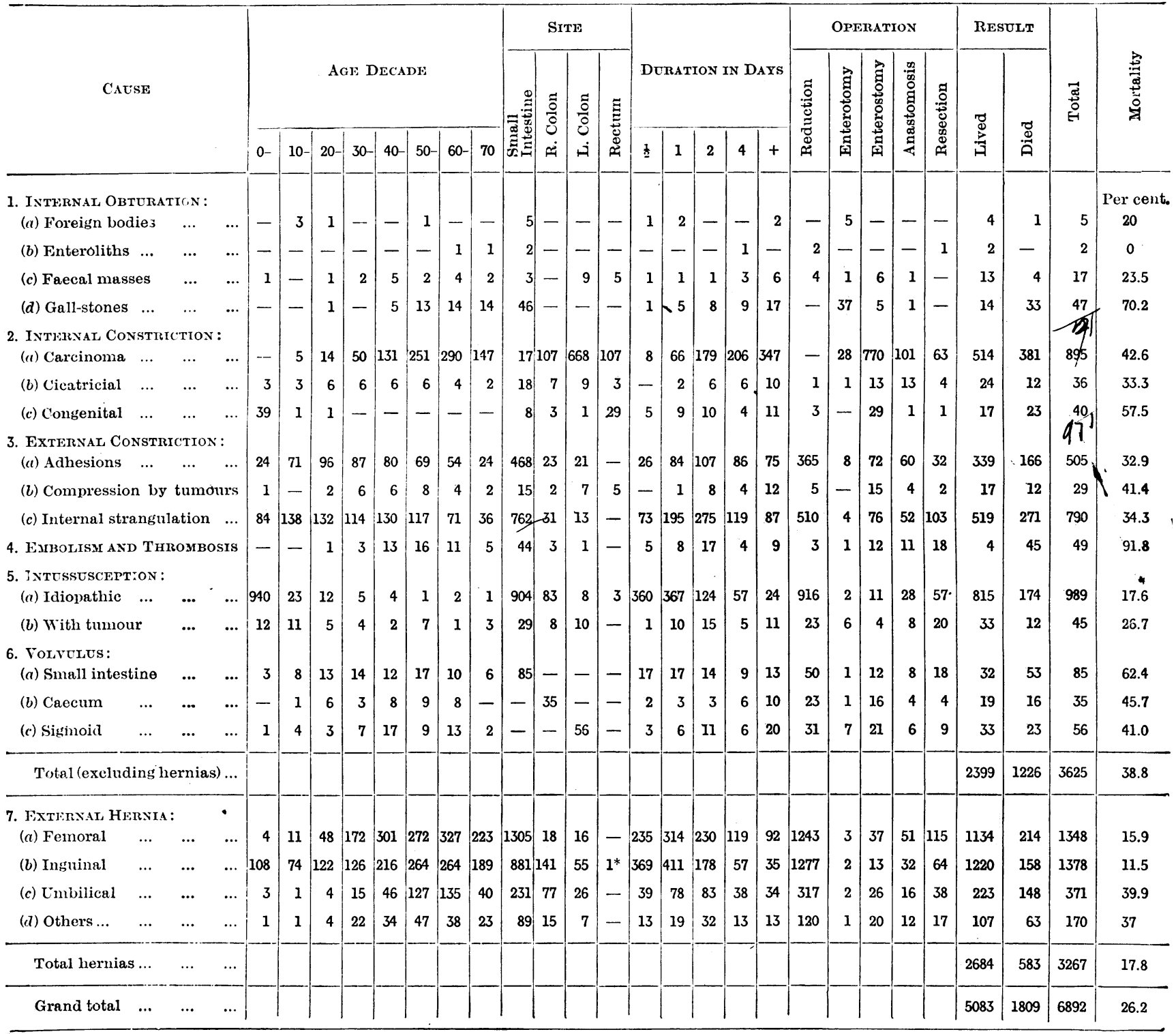

* Stomach

This table gives a detailed analysis of the various types of acute intestinal obstruction under the main headings and the subheadings. It shows the age incidence of acute obstruction of each type in the first set of columns. In the second set it gives the site of the obstruction; in the third, the duration of the disease from the onset to the day of operation; in the fourth, the actual operation performed; and finally, the survivals and deaths, the totals, and the percentage mortality. 
the graph-for example, out of 1,378 cases of strangulated inguinal hernia 158 patients died and 1,220 survived. In the smaller table you will see a comparison of mortality rates in the two sets of figures, years $1920-4$ and 1925-30.

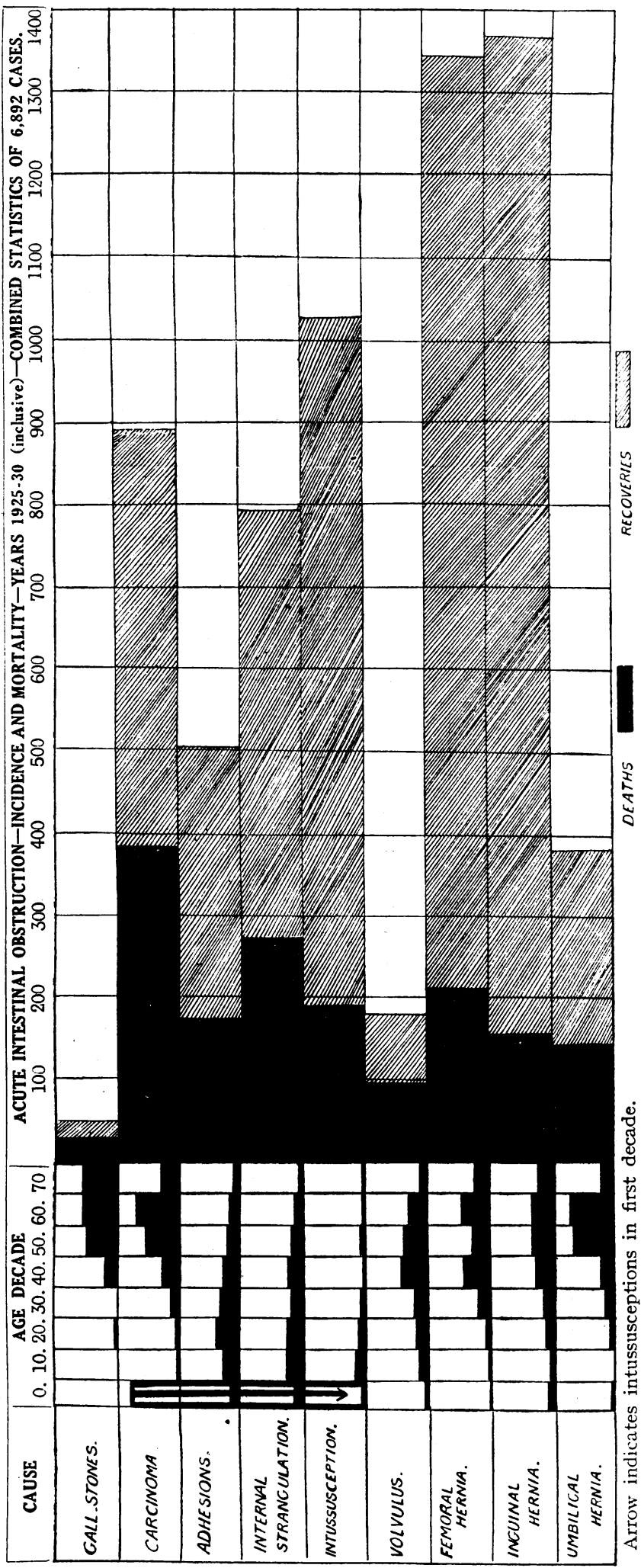

You will note that the mortality rate has been materially reduced in intussusception, and in inguinal and femoral hernia, especially when one considers that this is a much larger series.

And now to turn to the statistical table. I should like first of all to acknowledge the unstinted help of the people whose names are at the top of the table: without them this return could never have been made. The geographical distribution of the cases is interesting. The number of cases in the whole of the London hospitals is about the same as in the provinces, excluding Scotland. In London, the London Hospital heads the list with more than twice as many as any other hospital. In the provinces Newcastle has the largest number, and Manchester only eight cases less ; whereas in Leeds the number is 664. In Liverpool the small number is accounted for by the fact that all the records are not available. The arrangement of the figures in the columns speaks for itself ; on the left you have the age decade, followed by details of the site of the obstruction, of the duration of the disease-by which is meant the interval between the onset of the obstruction and the date of operation-and then follow the actual detail of the operation performed, the result, the totals, and the mortality.

The question that we must ask ourselves is whether we are going to sit down under these figures or whether

\begin{tabular}{|c|c|c|c|c|c|c|}
\hline & & & & & \multicolumn{2}{|c|}{ Mortality Per Cent. } \\
\hline & & & & & $1920-4$ & $1925-30$ \\
\hline Gall-stones... & $\ldots$ & $\ldots$ & $\ldots$ & $\ldots$ & 50 & 70.2 \\
\hline Carcinoma ... & $\ldots$ & $\ldots$ & $\ldots$ & $\ldots$ & 43.5 & 42.6 \\
\hline Adhesions ... & $\ldots$ & $\ldots$ & $\ldots$ & $\ldots$ & 31 & 32.9 \\
\hline Internal strang & ulatio & & $\ldots$ & $\ldots$ & 33 & 34.3 \\
\hline Intussusceptior & a (iodi & puath & & $\ldots$ & 22 & 17.6 \\
\hline Volvulus $\ldots$ & $\ldots$ & $\ldots$ & $\ldots$ & $\ldots$ & 51 & 52.2 \\
\hline Femoral hernis & $\ldots$ & $\ldots$ & $\ldots$ & $\ldots$ & 20 & 15.9 \\
\hline Inguinal hernis & a... & $\ldots$ & $\ldots$ & $\ldots$ & 16 & 11.5 \\
\hline Umbilical hern & & $\ldots$ & $\ldots$ & $\ldots$ & 35 & 39.9 \\
\hline
\end{tabular}

This small table shows the comparative mortality of the two series of statistics mentioned in the text-in the years 1920-24, 3,064 cases, and in the vears $1925-30,6,892$ cases. It shows a material reduction in mortality under the headings of intussusception, femoral and inguinal hernia. It is interesting that the total mortality in the two series is identical-26.2 per cent.

we can improve them, and we must realize that, excluding carcinoma and one or two minor headings, all these patients, if their condition is diagnosed early and treated early and efficiently, should live. Just picture the difference between the early and the late case of acute intestinal obstruction. We have all known that glorious feelingsay, when operating upon an obstruction by a bandof opening the abdomen, finding the little string tied across the bowel, cutting it, watching the intestine joyfully reopening its occluded lumen and passing on its contents, and of closing the wound, knowing well that we have saved that patient's life even more surely than if we had snatched him out of a fire. But unfortunately we have all experienced the other side when dealing with a late case of obstruction-a patient, moribund and cold ; when, remembering the old adage that "if you put a patient on the operating table cold you will take him off colder still," we have done everything in our power to improve the patient's condition sufficiently to make him even a sporting operative risk. Then we have opened the abdomen, probably under spinal anaesthesia, to let out a thin blood-stained fluid, followed by a gangrenous gut; and we have realized with a sickening sense of frustated endeavour that however quickly and efficiently we work the chance of success has been taken from us. If we accept the contention that by early diagnosis and treatment these people may be saved from miserable death, then these mortality rates are too high. And if by showing you these figures I have even in the smallest degree helped to reduce that mortality in the years to come, my labour has not been in vain. 